\title{
Artefak Rijang Situs Gua Pawon
}

\author{
Dinar Nurfaridah", Rochtri Agung Bawono, Kristiawan \\ Prodi Arkeologi, Fakultas Ilmu Budaya, Unud \\ [dinar.nay13@gmail.com],[rabawono@gmail.com@gmail.com], [iwan_trust@yahoo.co.id] \\ Bandung, Jawa Barat, Indonesia \\ *Corresponding Author
}

\begin{abstract}
Goa Pawon is a prehistoric site that very important to discover the growth of ancient society in the world. Not only found humans remains in Goa Pawon, but we also found so many artefacts and ecofact remains, one of the artefacts is a tool from chert. This research is intended to discover the variety type of chert tools and to uncover what is the function of every type of chert tools that used to sustain human life in Goa Pawon. Data collecting method used for this research is bibliography study, observation, and interview. All the finding then collected and analyzed. Research method used for this research is typology analysis method, and function analysis method. Typology theory, functional theory and behavior archaeology theory is use by the researcher to be the basic idea about the type and function of rijang that used by the humans of Goa Pawon. The findings of chert artefacts in Goa Pawon is split into two category, waste category and tools category. Waste category has flakes, debitage, and core. Tool category has edge scrapper, notched scrapper, end scrapper, danticulated scrapper, high-back scrapper, lancipan dan multi tools. All the tools in this site have so many form and made typical adjusted to what is for. Tendency for rijang is used to process animals, for example is pointer that was function to make a hole on animal bone and animal tooth and made to be a jewelry, and notched scrapper that used to dredge a molusca, Pelecypoda type.
\end{abstract}

Key words: Pawon Cave Site, chert, typology, stone tools.

\begin{abstract}
Abstrak
Situs Gua Pawon merupakan sebuah situs gua hunian yang keberadaannya sangat penting dalam menguak perkembangan peradaban prasejarah dunia. Tidak hanya ditemukan rangka-rangka manusia, namun teradapat temuan ekofak dan artefak lainnya dan salah satunya adalah artefak batu berbahan rijang. Penelitian ini memiliki tujuan untuk mengungkapkan variasi tipe artefak rijang serta mengungkapkan fungsi-fungsi dari setiap tipe alat batu rijang di Situs Gua Pawon. Metode pengumpulan data yang digunakan pada penelitian ini yaitu studi kepustakaan, pengamatan temuan rijang, dan wawancara. Temuan-temuan yang telah dikumpulkan, lalu dilakukan analisis. Metode penelitian yang dilakukan yaitu dengan metode analisis
\end{abstract}


tipologi dan analisis fungsi. Teori tipologi, teori fungsi, dan teori behavior archaeology digunakan sebagai pendukung penelitian serta dasar pemikiran penulis mengenai tipe-tipe alat batu rijang yang pernah dimanfaatkan oleh masyarakat pendukung Situs Gua Pawon. Temuan artefak rijang pada Situs Gua Pawon ini terbagi kedalam dua kategori, yaitu kategori limbah dan kategori alat. Pada kategori limbah terdapat serpih, tatal, dan juga batu inti. Kategori alat diantaranya yaitu serpih pakai, serut samping, serut cekung, serut ujung, serut bergerigi, serut berpunggung tinggi, lancipan dan multi tools. Seluruh alat batu yang dimiliki pada situs ini memiliki berbagai bentuk yang disesuaikan dengan fungsi atau tujuan alat tersebut dibuat. Kecenderungan pemakaian alat-alat batu rijang ini lebih dimanfaatkan untuk aktivitas dalam mengolah fauna, seperti misalnya lancipan yang berfungsi untuk melubangi perhiasan yang terbuat dari tulang maupun gigi hewan, kemudian serut cekung yang difungsikan untuk mengeruk daging moluska jenis Pelecypoda.

Kata kunci: Gua Pawon, artefak rijang, alat batu, tipologi.

\section{Pendahuluan}

Perubahan telah terjadi pada seluruh aspek di muka bumi ini termasuk keberadaan manusia. Kehidupan manusia telah dimulai sejak periode prasejarah pada Kala Plestosen yang sudah mengalami glasiasi berkali-kali (Poesponegoro,1993:1). Kehidupan manusia telah berlangsung sejak 1,8 juta tahun yang lalu dan terus berlanjut hingga masa kini. Perkembangan pola pikir manusia pada Kala Plestosen masih sangat sederhana. Hingga waktu 10.000 tahun yang lalu pada Kala Holosen barulah manusia mulai memperlihatkan perkembangan perilaku dan pola pikir mereka (Reawaru, 2005:2).

Manusia mulai mengembangkan kemampuan bertahan hidup pada tingkat awal kehidupan. Salah satunya adalah dengan mengasah kemampuan membuat alat. Bahan-bahan yang digunakan untuk membuat alat biasanya terbuat dari kayu, tulang maupun batu. Batu merupakan bahan alam yang mudah diperoleh manusia yang memiliki ketahanan yang lebih kuat dan tahan lama dibandingkan dengan bahan alam lainnya seperti kayu dan tulang (Poesponegoro,1993:3,25).
Bahan batuan yang biasanya digunakan bersifat keras tetapi masih mudah untuk dipangkas dan dibentuk, seperti batuan kalsedon, jasper, obsidian, andesit, dan rijang.

Teknologi pembuatan alat berbahan dasar batuan pun mulai berkembang, sehingga perkembangan kehidupan prasejarah di nusantara dapat diamati dari perkembangan hasil teknologi alat batu. Perkembangan tersebut diantaranya Paleolitik (masa batu tua) dengan budaya serpih bilah. Mesolitik atau masa batu tengah berupa munculnya teknologi mikrolit (Reawaru, 2005:2), dan Neolitik (masa batu muda) pada akhir Holosen yaitu penguasaan teknik pengupaman yang menghasilkan berbagai tipe beliung dan kapak serta gelang batu (Simanjuntak, 2008: 40).

Aktivitas manusia dalam menghasilkan alat batu puncaknya pada kala awal Holosen pada 30.000-10.000 tahun yang lalu di Jawa Barat (Simanjuntak, 2001; Yondri, 2013: 68) yaitu Perbukitan Gamping (Karst) Rajamandala (Koesumadinata, 1959) yang merupakan lokasi Gua Pawon berada (Yondri, 2013: 68). Situs Gua 
Pawon yang merupakan bagian dari tepian bagian barat Dataran Tinggi Kawasan Danau Bandung Purba ini secara administrasi terletak di Kawasan Bukit Batu Kapur Citatah, Formasi Rajamandala, Desa Gunung Masigit, Kecamatan Cipatat, Kabupaten Bandung Barat, Jawa Barat.

Situs Gua Pawon, sebelumnya beberapa kali pernah dilakukan penelitian yaitu oleh Candra Arifin (2013) dalam jurnalnya yang berjudul Penelitian Keragaman dan Etnobiologi Kelelawar dari Gua Pawon di Desa Gunung Masigit Karst Citatah. Pembahasan mengenai artefak jenis batuan lain seperti artefak jenis obsidian pun pernah dilakukan penelitian oleh Anton Ferdianto (2008) dalam jurnal yang berjudul Artefak Obsidian dari Gua Pawon.

Selain itu, Situs Gua Pawon lebih banyak dilakukan penelitian oleh Lutfi Yondri yang dibuktikan dari beberapa laporan penelitiannya yang telah ditulis dalam bentuk jurnal. Beberapa jurnal Lutfi Yondri diantaranya yaitu Budaya Obsidian di Tepian Danau Bandung Purba (2007), Analisis Pendahuluan Temuan Artefaktual Hasil Ekskavasi Gua Pawon, Karst Radjamandala-Jawa Barat (2006),dsb.

Situs Gua Pawon ini memiliki ketinggian 716 mdpl yang luasnya kurang lebih 9 hektar dengan panjang 38 meter dan lebar 16 meter (Ferdianto, 2008: 1819). Kondisi geologi Situs Gua Pawon terbagi kedalam tiga ruangan yang terhubung oleh jalan masuk dari bagian depan gua (Ferdianto, 2008: 11). Memiliki kondisi lantai gua yang sebagian rusak akibat erosi dan penambangan fosfat, juga memiliki atap gua sebagia runtuh dan sebagian pula masih utuh.

Kondisi vegetasi disekitar Situs Gua Pawon memiliki tingkat keendemikan yang tinggi. Selain itu kondisi fauna Situs Gua Pawon ini memiliki aneka berbagai macam jenis fauna yang mendukung kehidupan masyarakat pendukung situs tersebut pada Masa Prasejarah. Terdapat 220 individu hewan pada situs ini, 172 yaitu jenis mamalia, lalu kelompok Reptilia (15), fauna Carcharhiniformes (33), dan sisanya jenis moluska.

Temuan pada Situs Gua Pawon ini terbagi kedalam dua kategori yaitu, ekofak dan artefak. Temuan ekofak diantaranya yaitu, enam buah rangka manusia dengan kondisi terkubur dan posisi menelungkup, fragmen tulang binatang, dan juga moluska. Temuan artefak diantaranya yaitu, fragmen keramik, fragmen gerabah, alat tulang, perhiasan, dan artefak batu dengan jenis batuan kalsedon, andesit, jasper, gamping, obsidian, dan juga rijang (chert).

Batu rijang merupakan salah satu jenis batuan sedimen yang meliputi serangkaian batu kersikan dengan berbagai kadar silika. Batuan rijang banyak digunakan sebagai bahan alat batu karena memiliki syarat-syarat sebagai bahan baku alat batu diantaranya memiliki tingkat kekerasan yang cukup tinggi, kadar butiran halus, dan licin (Bordes, 1970: 9 ; Reawaru, 2005: 5152). Selain itu mempunyai arah pecahan yang dapat dikendalikan, serta pecahan yang dihasilkan cenderung tajam.

Umumnya, untuk melakukan pemangkasan terhadap batuan rijang ini harus dilakukan dengan cara pemangkasan secara langsung (direct) dengan cukup keras untuk dapat melepaskan serpihannya. Artefak rijang merupakan artefak batu yang mendominasi temuan di Situs Gua Pawon setelah obsidian.

Artefak rijang (chert) yang dijadikan sebagai data penelitian yaitu artefak rijang yang berada pada sektor selatan kotak S3T3 (2003, 2004), S4T4 (2004, 2005), S4T5 (2005), S2T3 (2010), dan S2T4 (2010). Artefak rijang yang ditemukan rata-rata berbentuk serpih, tatal dan juga batu inti dengan ukuran 
yang kecil dan juga besar. Beragam macam jenis, bentuk dan ukuran artefak rijang yang telah ditemukan pada Situs Gua Pawon.

\section{Pokok Permasalahan}

Berdasarkan uraian latar belakang diatas, maka ada dua rumusan masalah

a. Bagaimana tipe artefak rijang Situs Gua Pawon di Jawa Barat?

b. Bagaimana fungsi alat batu rijang Situs Gua Pawon berdasarkan tipologi di Jawa Barat?

\section{Tujuan Penelitian}

Tujuan penelitian ini adalah mengungapkakan viarisi tipe artefak rijang serta mengungkapkan fungsi alat batu rijang yang berada pada Situs Gua Pawon, Kabupaten Bandung Barat, Jawa Barat.

\section{Metode Penelitian}

Penelitian yang dilakukan dengan menggunakan pendekatan kualitatif dengan melakukan pengamatan terhadap temuan dan di deskripsikan dengan cara kualitatif. Penelitian ini juga dilakukan pendekatan kuantitatif dengan melakukan penghitungan jumlah temuan artefak rijang, dan melakukan perhitungan ratarata panjang, rata-rata lebar, serta ratarata tebal pada setiap artefak rijang Situs Gua Pawon.

Sumber data penelitian ini dibedakan menjadi dua, yaitu data primer dan data sekunder. Data primer yaitu himpunan artefak rijang dari kotak ekskavasi kotak S3T3 (2003, 2004), S4T4 (2004, 2005), S4T5 (2005), S2T3 (2010), dan S2T4 (2010) berasal dari Situs Gua Pawon yang secara administratitf terletak di Desa Gunung Masigit, Kecamatan Cipatat, Kabupaten Bandung. Saat ini data tersebut sudah dipindahkan dan berada di Balai Arkeologi Bandung. Data sekunder yaitu yang menunjang data primer.
Data sekunder yang dimaksud adalah data kepustakaan berupa laporan penelitian, buku jurnal, thesis dan skripsi mengenai Situs Gua Pawon dan temuan rijang. Metode analisis yang digunakan yaitu analisis tipologi dan analisis fungsi yang didukung oleh teori Tipologi, Teori Fungsional, dan Teori Behavior Archaeology untuk menjawab permasalahan yang telah dirumuskan.

\section{Hasil dan Pembahasan}

\subsection{Analisis Tipologi Artefak Rijang Situs Gua Pawon}

Artefak rijang yang dilakukan penelitian pada Situs Gua Pawon menghasilkan dua kategori yaitu non-alat dan alat. Temuan-temuan artefak rijang tersebut tersebar dalam Ruang III kotak galian ekskavasi yaitu kotak S3T3 (34) kategori non-alat 25 buah dan kategori alat 9 buah, kotak S4T4 (199) kategori non-alat 151 buah dan kategori alat 48 , kotak S4T5 (9) dengan hanya kategori non-alat 9 buah, kotak S2T3 (344) dengan kategori non-alat 199 dan kategori alat 145, serta kotak S2T4 (495) kategori non-alat 356 buah dan kategori alat 139 buah. Jumlah total keseluruhan artefak rijang yaitu sebanyak 1081 buah.

Persentase temuan artefak rijang yang ditemukan pada Situs Gua Pawon menunjukkan bahwa lebih didominasikan oleh temuan kategori non-alat atau limbah. Jenis limbah tersebut yaitu limbah jenis serpih $44 \%$ dan juga tatal yaitu $19 \%$. Kategori limbah dengan tipe batu inti merupakan limbah yang keberadaanya paling sedikit persentasenya dibandingkan dengan limbah serpih dan tatal, yaitu sebesar 5\%.

Persentase limbah batu inti ini mengungkapkan bahwa sangat minimnya jumlah bahan baku batuan rijang yang dibawa oleh masyrakat pendukung Situs Gua Pawon. Penulis berasumsi bahwa 
sedikitnya jumlah bahan baku batuan rijang ini diakibatkan oleh jarak yang cukup jauh antara wilayah Situs Gua Pawon dan wilayah Tasikmalaya sebagai sumber bahan baku batu rijang yang paling memungkinkan.

Pada kategori alat, persentase yang paling banyak sebesar $12 \%$ yaitu berupa tipe serpih pakai. Selanjutnya terdapat $6 \%$ artefak rijang merupakan tipe multi tools. Selanjutnya disusul dengan berbagai tipe kategori alat lainnya seperti serut samping (4\%), serut cekung (4\%), serut ujung (3\%), serut berpunggung tinggi $(2 \%)$, serut bergerigi $(1 \%)$, dan lancipan $(0 \%)$.

Berdasarkan diagram tersebut, dapat kita amati bahwa artefak rijang yang paling mendominasi pada kategori nonalat yaitu serpih dan pada kategori alat yaitu serpih pakai. Berdasarkan hasil diagram diatas, penulis berasumsi bahwa masyarakat pendukung pada masa itu ada kecenderungan memiliki pemikiran yang praktis dimana mereka cenderung menggunakan yang sudah ada, sehingga cenderung memanfaatkan langsung serpihan tanpa harus diolah. Barulah ketika mereka membutuhkan sesuatu untuk melakukan aktivitas yang lebih rumit, mereka mulai membuat alat-alat sesuai kebutuhan mereka saat itu.

Kategori alat yang jumlah persentasenya paling banyak setelah serpih pakai yaitu tipe multi tools. Berdasarkan hasil analisis tersebut, maka penulis beranggapan bahwa masyarakat pendukung Situs Gua Pawon cenderung lebih memanfaatkan bahan baku rijang seefektif mungkin dengan menjadikan satu serpih memiliki berbagai tipe alat. Hal tersebut dilakukan karena terbatasnya bahan baku batuan rijang yang dibawa oleh masyarakat pendukung Situs Gua Pawon. Keterbatasan bahan baku rijang ini yang memunculkan sebuah ciri khas dari kebudayaan alat batu dari masyarakat Situs Gua Pawon yaitu adanya multi tools ini.

Hampir seluruh tipe alat Situs Gua Pawon cenderung lebih dominan memiliki karakter retus dengan posisi direct, kemudian dengan letak retus berada pada bagian distal dengan sebaran retus continuous. Adapun ukuran alat batu rijang situs ini rata-rata berada pada kategori sedang, yang mana ukuran tersebut $3 \leq X \leq 6 \mathrm{~cm}$. Selain itu, alat batu rijang cenderung lebih banyak berbentuk geometri trapesium.

\subsection{Analisis Fungsi Artefak Rijang Situs Gua Pawon}

Persamaan faktor-faktor tipologi tersebut pada kenyataanya tidak mempengaruhi fungsi pada setiap tipe alat batu rijang Situs Gua Pawon ini. Hal tersebut dapat dibuktikan dari tipe alat serut samping dan serut cekung. Kedua tipe tersebut memilki karakter retus yang hampir keseluruhannya sama, serta bentuk geometrinya pun sama. Namun kedua tipe alat tersebut memiliki peran dan fungsi yang jauh berbeda. Hal tersebut disebabkan karena fungsi hanya akan dipengaruhi dari hasil akhir pembuatan alat, bukan dari bagaimana proses alat tersebut dibuat dan bukan berdasarkan adanya persamaan karakter tipologinya.

Kemungkinan terdapat adanya pola tertentu dengan memperhatikan kenyamanan pemakaian dalam membentuk alat-alat batu rijang, terutama pada serut yang berbentuk serpih. Aktivitas dalam pemanfaatan ala-alat batu rijang Situs Gua Pawon ini lebih cenderung melakukan pengolahan terhadap fauna sekitar. Hal tersebut didukung dengan temuan himpunan alat rijang yang mendominasi situs ini, juga konteks temuannya yang cenderung lebih banyak temuan fauna-fauna jenis mamalia, moluska, reptilian, dan jenis ikan-ikanan. 


\section{Simpulan}

Gua Pawon merupakan salah satu situs gua hunian pada masa prasejarah di Jawa Barat. Situs gua tersebut dimanfaatkan atau dihuni oleh masyarakat prasejarah pada Masa Mesolitik akhir menuju Masa Neolitik. Hal tersebut dibuktikan dari beberapa temuan seperti rangka manusia, fragmen tulang hewan, perhiasan dari tulang maupun gigi hewan, alat tulang, alat batu beserta limbah-limbahnya dari beragam macam jenis batu yaitu batu andesit, kalsedon, obsidian dan juga rijang.

Berdasarkan uraian diatas, maka terdapat beberapa kesimpulan yang penulis uraikan. Pertama, temuan artefak batu rijang yang ditemukan pada Situs Gua Pawon ini memiliki dua kategori, yaitu kategori alat dan non-alat. Artefak rijang yang termasuk dalam kategori alat diantaranya yaitu; serpih pakai, serut samping, serut cekung, serut bergerigi, serut ujung, serut berpunggung tinggi, multi rools, dan lancipan. Adapun artefak rijang yang termasuk dalam kategori nonalat anatara lain yaitu; limbah serpih, limbah tatal, dan limbah batu inti.

Kedua, alat batu rijang memiliki berbagai bentuk yang dimana disesuaikan oleh fungsi-fungsi atau tujuan alat tersebut dibuat. Temuan tersebut diantaranya yaitu, (a) Serpih pakai yang memiliki fungsi untuk menyerut sesuatu yang tidak terlalu lunak namun tidak terlalu keras, kemudian dimanfaatkan juga untuk menguliti faunan berukuran kecil, dan membersihkan lemak dan juga daging pada tulang yang kemungkinan tulang tersebut dimanfaatkan sebagai alat.

(b) Serut samping memiliki tajaman monofasial yang cenderung dilakukan untuk aktivitas mengiris daging-daging berukuran kecil. (c) Serut cekung pemanfaatannya cenderung mendekati pada aktivitas untuk mencongkel dan mengeruk daging moluska jenis
Pelecypoda. Serut cekung juga memungkinkan dimanfaatkan untuk mengeruk daging fauna lainnya. (d) Serut bergerigi cenderung mirip berbentuk gergaji. Hal tersebut tentulah menimbulkan kemungkinan bahwa alat ini difungsikan untuk aktivitas menggergaji tulang, mengeruk daging kerang, menguliti fauna yang cenderung berukuran kecil ke sedang.

Pemanfaatan serut bergerigi ini kemungkinan tidak hanya untuk fauna saja, tetapi dimanfaaatkan juga untuk menguliti dan memotong tanaman atau batang pohon. (e) Serut ujung memiliki peluang untuk dilakukan aktivitas menyerut atau membersihkan tulang yang akan dipersiapkan sebagai alat. Selain itu, serut ini pun kemungkinan difungsikan untuk memotong dan menguliti fauna berukuran kecil.

(f) Serut berpunggung tinggi ini cenderung untuk aktivitas pengetaman pada tuang yang hendak dijadikan sebagai alat maupun perhiasan. (g) Lancipan merupakan temuan yang cukup jarang ditemukan pada situs ini, dimanfaatkan sebagai alat untuk membuka cangkang kerang dan juga aktivitas melubangi tulang ataupun gigi yang dijadikan sebagai perhiasan. (h) Multi tools alat multi fungsi yang cenderung dimanfaatkan untuk banyak aktivitas yang tergantung pada tipe-tipe yang dibuat pada satu buah alat multi tools ini. Pemanfaatan yang lebih sering dilakukan pada tipe multi tools ini yaitu menguliti daging, menyerut tulang, mengeruk cangkak kerang Pelecypoda, dan juga untuk memcahkan ujung cangkak moluska Gastropoda untuk diambil dagingnya. 


\section{Daftar Pustaka}

Arifin, Candra, Ruhyat Partasamita, dan Teguh Husodo. 2013. "Penelitian Keragaman dan Etnobiologi Kelelawar dari Gua Pawon di Desa Gunung Masigit Karst Citatah", Biotika Jurnal Ilmiah Biologi. Bandung: Uniersitas Padjajaran.

Chia, Stephen, Lutfi Yondri, dan Truman Simanjuntak. 2007. "The Origin of The Obsidian Artifacts from Pawon Cave and Bukit Karsamanik, Bandung-Indonesia", Selisik Masa Lalu. Bandung: Ikatan Ahli Arkeologi Indonesia.

Ferdianto, Anton. 2008. "Artefak Obsidian dari Gua Pawon”. Depok: Universitas Indonesia.

Irdiansyah. 2008. "Fungsi Alat Batu dari Situs Gua Pandan, Sumatera Selatan”. Depok: Universitas Indonesia.

Poesponegoro, Marwati Djoened dkk. 1993. Sejarah Nasional Indonesia I, Edisi ke-4. Jakarta: Balai Pustaka.

Rahim, Abdur. 2014. "Pemanfaatan Moluska Pada Situs Gua Pawon, Kabupaten Bandung, Jawa Barat”. Depok: Universitas Indonesia.

Radiansyah, Danny. 2010. "Gigi Hewan dari Sitsu Gua Pawon (Jawa Barat): Identifikasi Hewan, Habitat dan Pemanfaatan". Depok: Universitas Indonesia.

Reawaru, Stevanus. 2005. "Karakteristik dan Perkembangan Industri Litik Kala Holosen di Situs Song Terus, Pacitan, Jawa Timur”.
Yogyakarta: Universitas Gajah Mada.

Simanjuntak, Truman, Yuniawati, Dwi Yani, Harkantiningsih, Naniek, Hardiati, Endang Sri, Wibisono, Sonny, dan Aziz, Fadhila Arifin. 2008. Metode Penelitian Arkeologi. Jakarta: Pusat Penelitian dan Pengembangan Arkeologi Nasional Badan Pengembangan Sumberdaya Kebudayaan Pariwisata Departemen Kebudayaan dan Pariwisata.

Suastika, I Made. 2007. "Hasil Penelitian Situs Gua Gede, Desa Pejukutan, Kecamatan Nusa Penida, Kabupaten Klungkung, Bali, Berita Penelitian Arkeologi. Denpasar: Balai Arkeologi Denpasar.

Yondri, Lutfi. 2004. "Laporan Kegiatan Ekskavasi di Situs Gua Pawon, Desa Gunung Masigit, Kabupaten Bandung, Jawa Barat”. Bandung: Balai Arkeologi Bandung.

Yondri, Lutfi. 2005. "Laporan Hasil Penelitian di Kecamatan Ciranjang dan Sekitarnya Serta Ekskavasi Lanjutan di Situs Gua Pawon Kawasan Karst Rajamandala Lembar Cianjur". Bandung: Balai Arkeologi Bandung. (Tidak Diterbitkan)

Yondri, Lutfi. 2006. "Analisis Pendahuluan Temuan Artefaktual Hasil Ekskavasi Gua Pawon, Karst Radjamandala-Jawa Barat" Widyasancaya. Bandung: Ikatan Ahli Arkeologi Indonesia.

Yondri. 2007. "Budaya Obsidian di Tepian Danau Bandung Purba" 
Widyasparuman. Bandung: Ikatan Ahli Arkeologi Indonesia.

Yondri, Lutfi. 2013. "Gua Ketuk di Kawasan Karst Pasir Pawon

Kandungan Budaya dan Pertanggalan C14". Bandung:

Balai Arkeologi Bandung. 